\title{
Diagnostic challenge and importance of the clinical approach of the Developmental Coordination Disorder
}

\author{
Lisseth Barra Cabello, Magister ${ }^{a}$
}

\begin{abstract}
The developmental coordination disorder is a common neurodevelopmental condition about which health professionals know very little. Consequently, children often go undiagnosed and are rarely treated. Anupdated synthesis of the topic is presented to provide recommendations for the diagnosis and treatment from the perspective of the clinician and from a public health approach. Theories explaining motor difficulties present in this disorder are briefly included.Clinical features and reasons rendering the diagnosis difficult are described as follows. Some of the existing recommendations are underscored and tools that could be used for the evaluation are described. Finally, treatment approaches for these children are determined considering that the disorder affects not only the child's motor performance, but also his or her academic, social and emotional performance and even his or her physical health.

Key words: developmental coordination disorder, dyspraxia, child, diagnosis, treatment.
\end{abstract}

http: / / dx.doi.org/ 10.5546/ aap.2019.eng.199

To cite: Barra Cabello L. Diagnostic challenge and importance of the clinical approach of the Developmental Coordination Disorder. Arch Argent Pediatr 2019;117(3):199-204.

a. Department of Kinesiology, School of Medicine, Universidad de Chile, Santiago, Chile.

E-mail address: Lisseth Andrea Barra Cabello, Magister: lisseth@uchile.cl

\section{Funding:}

None.

Conflict of interest: None.

Received: 5-22-2018 Accepted: 11-8-2018
Children suffering from DCD have a poor motor performance and can have problems in the psychosocial setting and in their physical health. They experience significantly increased symptoms of depression and anxiety, ${ }^{9}$ have a low perception of self-efficacy, which is related to a low motivation to participate in social and physical activities. ${ }^{10}$ Additionally, they have a higher body mass and waist circumference, both risk factors associated with cardiovascular disease and type 2 diabetes. ${ }^{10}$ Besides, children with DCD and their parents report having a significantly worse healthrelated quality of life compared to normative data. ${ }^{11}$

In terms of frequency of DCD, a prevalence of $5-6 \%$ is described. ${ }^{8}$ This means that, in a class of 25 students, at least one would suffer from it. Compared to DCD, cerebral palsy occurs in 2 out of 1000 children, and autism spectrum disorders in 1 out of $100 .{ }^{8,13}$ Therefore, it can be ascertained that DCD is more common than other disorders, yet unknown to many health professionals. ${ }^{14,15}$ In a study, only $41 \%$ of pediatricians were aware of the disease. ${ }^{16}$ In another study conducted to determine the impact of an educational program on improving clinical management in children with DCD, it was found that, at the start of the study, $91.1 \%$ of the doctors were not aware of it, and only $1.6 \%$ considered that they would be able to diagnose a child with this disease. ${ }^{17}$ This lack of awareness leads to many children going undiagnosed or being diagnosed late. In this regard, another study reported that the average time it took to make a diagnosis was two and a half years after parents had consulted about motor difficulties 
they observed in their children. ${ }^{18}$

There has been a growing body of research on this disorder ${ }^{19}$ and there are recommendations for its approach. ${ }^{20-22}$ Most of these articles are in English, so it has been recommended to translate existing information to increase knowledge among health professionals..$^{21}$ The objective of this review is to present an updated synthesis of the disorder and provide general recommendations for its approach from the perspective of the clinician and from a public health approach taking into account the different levels of prevention.

\section{How can motor difficulties observed in the developmental coordination disorder be explained?}

There is still no consensus about which theory best explains how motor control and motor learning take place. ${ }^{23}$ An appropriate model would be the theory of dynamic systems, which considers that movement results from the interaction of multiple subsystems selforganized by the individual, and in which there is a constant interaction between the child's resources, the environmental context and the task to be performed. ${ }^{24}$

There are several hypotheses about motor difficulties present in children with DCD. One of them is the sensory integration theory according to which the child cannot adequately process sensory stimuli, and therefore his or her motor response is inappropriate to the context. ${ }^{25}$ For example, the poor visual-spatial processing described among these children would be one of the underlying causes of the disorder. ${ }^{26}$ Another hypothesis is that of the internal modeling deficit, which indicates that children with DCD have problems generating and/or monitoring a mental representation of motor actions, thus having significant limitations in their ability to plan and control movement. ${ }^{27,28}$

The complexity in DCD poses challenges in attempts to understand the mechanisms underpinning motor skills and how these relate to organization of behavior and emotion. Recently, a new framework was presented to consider participatory contexts that reflect the fluid and transactional nature of dynamic interactions between the person, the activity and environmental interfaces. ${ }^{10}$

\section{The challenge and importance of diagnosis}

DSM-5 establishes the criteria required for the diagnosis of DCD. ${ }^{8}$ The first one is that the acquisition and execution of coordinated motor skills is substantially below that expected given the individual's chronological age and opportunity for skill learning and use. The second one is that this motor skill deficit significantly and persistently interferes with activities of daily living and has an impact on academic productivity. The third one is that the onset of described signs is in the early developmental period. Finally, intellectual disability, visual impairment and other neurological conditions affecting movement should be ruled out. Therefore, any child who meets the first three criteria must be evaluated by a pediatric neurologist, who should rule out that problems observed are due to an alteration in the nervous system compromising movement, such as cerebral palsy, muscular dystrophy, among others.

This disorder is usually not recognized or diagnosed by physicians, ${ }^{14,21,29,30}$ because no clear neurological signs are found at the time of the physical examination. ${ }^{31}$ The child with DCD has difficulties with manipulative skills, when catching and/or guiding a moving object, when performing activities that involve balance, among others. He or she may display poor motor performance, which is also variable, depending on the degree of involvement and the time when the motor task is executed. ${ }^{31,32}$

Parents are those who often notice that a child has motor difficulties when compared to others of the same age. But when uninformed health professionals are consulted; they point out that these children present no difficulties. Hence, there is a tendency to think that these children are simply floppy, which is why parents and teachers' demands are maintained. Children begin to feel continuously frustrated and their self-esteem progressively decreases, because they fail to perform motor tasks as desired. Missiuna et al., describe a developmental trajectory in DCD in which there are motor and game deficits in early childhood, then difficulties in developing self-care and peer problems in middle childhood, and later, poor self-concept and emotional health in late childhood and adolescence. ${ }^{30}$ In the most favorable cases, after parents have experienced the frustration of consulting with various specialists, the diagnosis comes late, ${ }^{29}$ because although motor difficulties are present since early development, most children are not diagnosed before the age of 5 , when school requirements make the disorder evident. ${ }^{18}$

To facilitate the diagnosis of DCD, a number of 
key questions have been described for use in the history taking process and there are suggestions on how to guide the physical examination. ${ }^{15}$ There is also an algorithm on how to guide the diagnostic process based on the criteria outlined in DSM-5. ${ }^{22}$ Furthermore, it is recommended that the diagnosis is made by a multidisciplinary team of qualified professionals composed of, among others, a physician and a kinesiologist or an occupational therapist trained in the use of standardized motor tools. ${ }^{20}$

Considering the foregoing, the following recommendations can be inferred with regard to the diagnostic approach to DCD. The first one is "to educate clinicians and the community at large to be able to identify children who are likely to have this disorder." ${ }^{18,21}$ The second one is "to establish primary prevention strategies aimed at favoring psychomotor development" by offering opportunities for children to engage in a variety of motor experiences enabling them to reach their optimum potential. This could be accomplished through public policies linked to childhood, ${ }^{33}$ which would facilitate the diagnosis by decreasing the frequency of children with a poor motor performance due to the lack of sensorimotor experiences. In addition, this would be an appropriate strategy to approach suspected cases, so that, while the diagnostic process is in progress, a better approach is provided, and those cases that, in fact, do not correspond to children with DCD are ruled out. Because of the large amount of time children spend in schools, they have been identified as an important setting to enable and promote physical activity programs. ${ }^{34}$

A third recommendation is "to check whether motor difficulties that encouraged parents to seek consultation are present." This evaluation can be performed by physiotherapists and / or occupational therapists specialized and experienced in the use of standardized motor development assessment tools. Of these, the most widely used to detect DCD is the Movement Assessment Battery for Children, second edition (MABC-2), ${ }^{22}$ of which there is a Spanish version. ${ }^{35}$ The International Classification of Functioning, Disability and Health, Version for Children and Youth (CIF-IA), ${ }^{36}$ instrument that shows how motor impairments limit activities and restrict participation of children with DCD in social settings, could be used to examine the impact of motor problems on activities of daily living. ${ }^{37}$

Another screening tool is the Developmental Coordination Disorder Questionnaire, which has also been translated and validated in Spanish, ${ }^{38}$ and is used to identify children at risk for having this disorder. However, it should be noted that its usefulness in children with a high neurological risk (such as premature infants) has been questioned, since the presence of the disorder would be underestimated. ${ }^{39}$ This may be because parents of these children are warned that they may have severe neurological sequelae, such as cerebral palsy, so when seeing that their child acquires important motor skills, such as walking, they are unable to identify DCD motor difficulties. Those who were extremely preterm infants, small-forgestational age, and those who began walking independently at 15 months or older, among others, are also considered at risk for DCD. ${ }^{15}$

Considering the aforementioned, a fourth recommendation would be "to carry out secondary prevention strategies in the population at risk of having DCD". ${ }^{40}$ These screening activities should focus on those children most likely to have this disorder and those with disorders associated with frequent comorbidities. In the case of children with attention deficit hyperactivity disorder (ADHD), a prevalence of DCD as high as $55 \%$ has been described. ${ }^{41}$ In those with a history of extreme prematurity, prevalences of up to $42 \%$ have been reported. ${ }^{42}$ In the case of the latter, the establishment of neurodevelopmental follow-up programs ${ }^{43-45}$ has been recommended, in which DCD assessment could be considered among children who do not have relevant neurological sequelae.

\section{Treatment approach to the child with developmental coordination disorder}

The next challenge is the treatment approach, since, even when children are diagnosed, they often face long waiting times before receiving the required care. ${ }^{46}$ In the past, it was thought that motor clumsiness was due to a delay in maturation and that the child would spontaneously overcome the problem. Today, it is understood that the child would not overcome this problem, ${ }^{15}$ and hence, it should be considered as a chronic disorder. Despite this, functional outcomes can be improved with appropriate interventions, so it is recommended that all children with DCD receive them. ${ }^{20}$

The treatment objective will be to achieve the highest possible motor performance to favor a greater autonomy of children in relation to activities of daily living and their social participation. Therefore, tertiary prevention of 
this disorder should not only focus on taking care of motor difficulties, but also on improving the quality of life and preventing secondary complications, such as overweight due to the lack of physical activity.

In general, treatments for DCD have been less well studied than the difficulties these children have. ${ }^{22}$ With respect to the types of interventions focused on the motor problem, traditionally, two approaches have been described. ${ }^{24,37}$ The first one relates to interventions focused on the underlying aspects of sensory processing and of the neuromadurative development with the aim of normalizing and/or improving movement. An example of this approach is the sensory integration therapy. The second approach involves treatments that use problemor task-solving processes that emphasize the contextual factors that intervene in it with the aim of improving children's functionality and participation. The ecological intervention and the Cognitive Orientation Program to Daily Occupational Performance (CO-OP) are part of it. More recently, some authors have added a multi-level approach (combining both mentioned above $)^{47}$ or have classified interventions using the CIF-IA approach. ${ }^{48}$ Regarding the usefulness of treatments, motor skills interventions have been shown to be effective in improving motor competence and cognitive, emotional and psychological performance in children. ${ }^{47} \mathrm{In}$ addition, results of another review showed that activity-oriented and body function-oriented interventions could have a positive effect on motor function and skills. ${ }^{48}$

Along with the above interventions, parents and teachers must be prepared to appropriately meet children's needs in family and school contexts. ${ }^{49}$ As they get older, people with DCD can learn to use compensatory strategies and adapt their occupations to those that have less demand for motor coordination, strategies which will eventually lead to a positive outcome in adulthood.

In addition, it should be noted that many children with DCD have comorbidities, such as ADHD and learning and/or language problems. ${ }^{50}$ Therefore, apart from diagnosing and treating DCD, it is important to address comorbidities that might be concurrent but also consequent to the evolution of the disorder, such as psychoemotional problems, overweight, and others. Comorbidities can affect the quality of life of children with DCD to a greater extent than the motor disorder.

\section{CONCLUSIONS}

There is little information describing this disorder in Spanish available to clinicians who need to begin to understand it. This article provides an updated description, explores the topic and offers general guidance on how to approach the disorder from a public health standpoint. It is consistent with what Camden et al. have pointed out in that the implementation of clearly defined protocols would be appropriate so that children with DCD are able to access diagnostic and treatment options. ${ }^{21}$

The approach to DCD should include public health strategies for primary, secondary and tertiary prevention measures. As a primary prevention strategy, education about the disorder should be provided to the community at large, but with greater emphasis on health professions that operate in the neurological or pediatric rehabilitation setting. Besides, good public policies aimed at childhood offer children the opportunity to achieve their optimal developmental potential and reduce the number of children with motor delay due to the lack of sensorimotor experiences. These measures would favor the timely diagnosis and treatment of children with DCD.

Screening for children with DCD, as a secondary prevention measure, should be applied to children most likely to have this disease and to those with a history of prematurity and/or comorbid disorders.

At the tertiary level, it should be noted that the comprehensive rehabilitation of children with DCD should include interventions addressing their poor functional performance and others reducing the impact of DCD on other areas of children's lives, including psychosocial aspects and the overall physical status. A communitybased rehabilitation approach might be appropriate to favor the inclusion of children with DCD and to reduce health costs, remembering that the school setting is where children mainly spend most of their time.

\section{Acknowledgments}

We would like to thank Elizabeth Fernández, physiotherapist and professor at the School of Kinesiology at Universidad de Chile for reviewing the draft manuscript and making corrections that improved its writing.

\section{REFERENCES}

1. Artigas-Pallarés J. Problemas asociados a la dislexia. Rev 
Neurol. 2002; 34(Supl 1):S7-13.

2. Magalhães LC, Missuina C, Wong S. Terminology used in research reports of developmental coordination disorder. Dev Med Child Neurol. 2006; 48(11):937-41.

3. GibbsJ,AppletonJ, AppletonR.Dyspraxia or developmental coordination disorder? Unravelling the enigma. Arch Dis Child. 2007; 92(6):534-9.

4. García-Nonell C, Rigau-Ratera E, Artigas-Pallarés J. PerfilNeurocognitivo del trastorno de aprendizaje no verbal. Rev Neurol. 2006; 43(5):268-74.

5. Málaga Diéguez I, Arias Álvarez J. Los trastornos del aprendizaje. Definición de los distintos tipos y sus bases neurobiológicas. Bol Pediatr. 2010; 50(211):43-7.

6. Díaz-Lucero AH, Melano CA, Etchepareborda MC. Síndrome de Déficit de atención, del control motor y de la percepción (DAMP): perfil neuropsicológico. Rev Neurol. 2011; 52(Supl 1):S71-5.

7. WorldHealthOrganization. CIE-10. Trastornos mentales y del comportamiento. Descripciones; clínicas y pautas para el diagnóstico. Geneva: WHO; 1992.

8. American Psychiatric Association. Diagnostic and Statistical Manual of Mental Disorders. 5.a ed. Washington, DC: American Psychiatric Association; 2014.

9. Zwicker J, Harris S, Klassen A. Quality of life domains affected in children with developmental coordination disorder: a systematic review. Child Care Health Dev. 2013; 39(4):562-80.

10. Green D, Payne S. Understanding Organisational Ability and Self-Regulation in Children with Developmental Coordination Disorder. Curr Dev Disord Rep. 2018; 5(1):3442.

11. Joshi D, Missiuna C, Hanna S, Hay J, et al. Relationship between BMI, waist circumference, physical activity and probable developmental coordination disorder over time. Hum Mov Sci. 2015; 40:237-47.

12. Karras HC, Morin DN, Gill K, Izadi-Najafabadi S. Healthrelated quality of life of children with Developmental Coordination Disorder. Res Dev Disabil. 2018 [Epub ahead of print]

13. Odding E, Roebroeck ME, Stam HJ. The epidemiology of cerebral palsy: Incidence, impairments and risk factors. Disabil Rehabil. 2006; 28(4):183-91.

14. Novak C, Lingam R, Coad J, Emond A. Providing more scaffolding': parenting a child with developmental coordination disorder, a hidden disability. Child Care Health Dev. 2012; 38(6):829-35.

15. Harris S, Mickelson E, Zwicker J. Diagnosis and management of developmental coordination disorder. CMAJ. 2015; 187(9):659-65.

16. Gaines R, Missiuna C, Egan M, McLean J. Educational outreach and collaborative care enhances physician's perceived knowledge about Developmental Coordination Disorder. BMC Health Serv Res. 2008; 8:21.

17. Wilson BN, Neil K, Kamps PH, Babcock S. Awareness and knowledge of developmental co-ordination disorder among physicians, teachers and parents. Child Care Health Dev. 2013; 39(2):296-300.

18. Alonso-Soriano C, Hill EL, Crane L. Surveying parental experiences of receiving a diagnosis of developmental coordination disorder (DCD). Res Dev Disabil. 2015; 4344:11-20.

19. Smits-Engelsman BC, Magalhães LC, Oliveira MA, Wilson PH. DCD research: How are we moving along? Hum Mov Sci. 2015; 42:289-92.

20. Blank R, Smits-Engelsman B, Polatajko H, Wilson P. European Academy for Childhood Disability (EACD): Recommendations on the definition, diagnosis and intervention of developmental coordination disorder (long version). Dev Med Child Neurol. 2012; 54(1):54-93.

21. Camden C, Wilson B, Kirby A, Sugden D, et al. Best practice principles for management of children with developmental coordination disorder (DCD): results of a scoping review. Child Care Health Dev. 2014; 41(1):147-59.

22. Smits-Engelsman B, Schoemaker M, Delabastita T, Hoskens J, et al. Diagnostic criteria for DCD: Past and future. Hum Mov Sci. 2015; 42:293-306.

23. Cano-de-la-Cuerda R, Molero-Sánchez A, CarrataláTejada M, Alguacil-Diego I, et al. Teorías y modelos de control y aprendizaje motor. Aplicaciones clínicas en neurorrehabilitación. Neurología. 2015; 30(1):32-41.

24. Sugden D. Current approaches to intervention in children with developmental coordination disorder. Dev Med Child Neurol. 2007; 49(6):467-71.

25. Ayres AJ. Sensory Integration and the Child. Los Angeles: Western Psychological Services; 1979.

26. Piek J, Dyck M. Sensory-motor deficits in children with developmental coordination disorder, attention deficit hyperactivity disorder and autistic disorder. Hum Mov Sci. 2004; 23(3-4):475-88.

27. Gabbard C, Cacola P. Losniños con trastorno del desarrollo de la coordinación tienen dificultad con la representación de las acciones. Rev Neurol. 2010; 50(1):33-8.

28. Adams I, Lust J, Wilson P, Steenbergen P. Compromised motor control in children with DCD: A deficit in theinternal model? A Systematic review. Neurosci Biobehav Rev. 2014; 47:225-44.

29. Missiuna C, Moll S, King S, Law M, et al. "Missed and misunderstood": Children with coordination difficulties in the school system. Int J Spec Educ. 2006; 21(1):53-67.

30. Missuina C, Moll S, King S, King G, et al. A trayectory of troubles: parents' impressions of the impact of developmental coordination disorder. Phys Occup Ther Pediatr. 2007; 27(1):81-101.

31. ChangS, YuN.Comparison of motor praxisand performance in children with varying levels of developmental coordination disorder. Hum Mov Sci. 2016; 48:7-14.

32. Smits $\square$ Engelsman B, Wilson P. Noise, variability, and motor performance in developmental coordination disorder. Dev Med Child Neurol. 2013; 55(Suppl 4):69-72.

33. BerlinskiS, Schady N (eds.). Los primeros años. El bienestar infantil y el papel de las políticas públicas. Washington DC: Banco Interamericano del Desarrollo; 2015.

34. Amador-Ruiz S, Gutierrez D, Martínez-Vizcaíno V, Gulías-González R, et al. Motor competence levels and prevalence of developmental coordination disorder in Spanish children: the MOVI-KIDS study.J Sch Health. 2018; 88(7):538-46.

35. Ruiz Perez L, Graupera-Sanz J. MABC-2. Batería de evaluación del movimiento para niños-2. Madrid:Pearson; 2012.

36. WorldHealthOrganization. Clasificación Internacional del Funcionamiento de la Discapacidad y de la Salud: Versión para la infancia y adolescencia. Madrid: Ministerio de Sanidad, Política Social e Igualdad: 2011.

37. Zwicker J, Missiuna C, Harris S, Boyd L. Developmental coordination disorder: A review and update. Eur J Paediatr Neurol. 2012; 16(6):573-81.

38. Salamanca Duque LM, Naranjo Aristizábal MM, González Marín AP. Traducción al español del cuestionario para diagnóstico de trastorno del desarrollo de la coordinación. Rev Cienc Salud. 2012; 10(2):31-42.

39. Roberts G, Anderson P, Davis N, De Luca C, et al. Developmental Coordination disorder in geographic cohorts of 8-year-old children born extremely preterm or extremely low birthweight in the 1990s. Dev Med Child Neurol. 2011; 53(1):55-60. 
40. Smits-Engelsman BC, Blank R, Van der Kaay AC, Mosterdvan der Meijs R, et al. Efficacy of interventions to improve motor performance in children with developmental coordination disorder: a combined systematic review and meta-analysis. Dev Med Child Neurol. 2013; 55(3):229-37.

41. Watemberg N, Waiserberg N, Zuk L, Lerman-Sagie T. Developmental coordination disorder in children with attention-deficit-hyperactivity disorder and physical therapy intervention. Dev Med Child Neurol. 2007; 49(12): 920-5.

42. Goyen TA, Lui K. Developmental coordination disorder in "apparently normal" schoolchildren born extremely preterm. Arch Dis Child. 2009; 94(4):298-302.

43. American Academy of Pediatrics. Follow-up Care of HighRisk Infants. Pediatrics. 2004; 114(Suppl 5):1377-97.

44. Robles Vizcaino MC, Poo Argüelles MP, Poch Olivé ML. Atención Temprana: recursos y pautas de intervención en niños de riesgo o con retrasos del desarrollo. Protocolos de la AEP. 2008; 37:278-85.

45. Grupo de Seguimiento de Recién Nacidos de Alto Riesgo SeguiSIBEN. Guía para el seguimiento de los tres primeros años de RN prematuros de Muy Bajo Peso al Nacer. Sociedad Iberoamericana de Neonatología; 2010. [Accessed on: November $\left.9^{\text {th }}, 2018\right]$. Available at: www.neopuertomontt. com/Seguimiento_Neonatal/Seguimiento_Siben.pdf.

46. Dunford C, Street E, O'Connell H, Kelly J, et al. Are referrals to occupational therapy for developmental coordination disorder appropriate? Arch Dis Child. 2004; 89(2):143-7.

47. $\mathrm{Yu}$ JJ, Burnett AF, Sit $\mathrm{CH}$. Motor Skill Interventions in Children With Developmental Coordination Disorder: A Systematic Review and Meta-Analysis. Arch Phys Med Rehabil. 2018; 99(10):2076-99.

48. Smits-Engelsman B, Vinçon S, Blank R, Quadrado VH, et al. Evaluating the evidence for motor-based interventions in developmental coordination disorder: A systematic review and meta-analysis. Res Dev Disabil. 2018; 74:72-102.

49. Sugden DA, Chambers ME. Intervention in children with developmental coordination disorder: The role of parents and teachers. Br J Educ Psychol. 2003; 73(Pt 4):545-61.

50. King-Dowling S, Missiuna C, Rodriguez MC, Greenway $\mathrm{M}$, et al. Co-occurring motor, language and emotionalbehavioral problems in children 3-6 years of age. Hum Mov Sci. 2015; 39:101-8. 